\section{(อ) OPEN ACCESS}

\title{
Sepsis-induced digital ischaemia in a professional pianist, in the absence of vasopressors
}

\author{
Vishnu Kurup, R Scott Simpson
}

Intensive Care, Barwon Health, Geelong, Victoria, Australia

\section{Correspondence to Dr Vishnu Kurup;} vishnu.k13@gmail.com

Accepted 27 September 2019

Check for updates

(c) BMJ Publishing Group Limited 2019. Re-use permitted under CC BY-NC. No commercial re-use. See rights and permissions. Published by BMJ.

To cite: Kurup $V_{t}$ Simpson RS. BMJ Case Rep 2019;12:e229659. doi:10.1136/bcr-2019229659

\section{SUMMARY}

Peripheral limb ischaemia and gangrene are devastating complications of pneumococcal sepsis. We report a 43-year-old professional pianist who presented with early sepsis and rapid development of this syndrome. No vasopressor medication was ever administered. We urgently reviewed the medical literature on a range of therapies recommended by consulting teams, to ensure he received optimal care. Based on our review and on feedback from the patient himself, we gained valuable insights into this illness and the merits of selected treatment options. His fingers ultimately recovered their function, intact, although several toes were later amputated. More recently published reviews postulate that imbalances in coagulation factors and natural anticoagulants occur as a result of disseminated intravascular coagulopathy and 'shock liver' in the sepsis syndrome, leading to microcirculatory thromboses. We submit this report as we believe it supports this hypothesis and adds further valuable information. We hope our observations will assist other critical care clinicians confronting this serious condition.

\section{BACKGROUND}

Streptococcuspneumoniae causes more deaths through sepsis, worldwide, than any other single pathogen. ${ }^{12}$ Symmetric peripheral gangrene develops in up to $6 \%$ of adults with pneumococcal sepsis, associated with a mortality of $50 \%$ and often leaves survivors with a considerable burden of morbidity. ${ }^{34}$ Medical literature on this topic is limited to case reports and small case series, and reviews of these reports. Considerable uncertainty exists regarding the underlying pathophysiology. The current hypotheses include intense vasoconstriction, a procoagulant phase of acute disseminated intravascular coagulopathy (DIC) and a low-flow state of the peripheral circulation, which may all combine to create the perfect situation for microcirculatory thrombi to form. ${ }^{56}$ Sudden, severe hepatic dysfunction, or 'shock liver', has been noted in up to $90 \%$ of cases. ${ }^{6}$ The contribution, if any, of therapeutically administered vasopressors to the syndrome is controversial. We believe this case is enlightening as the syndrome developed rapidly and impressively in a patient with features of early sepsis and mild markers of 'shock liver', in the absence of vasopressors. Our motivation to secure our patient's optimal recovery led us to review the available literature and consult widely for advice, and led him to provide articulate feedback about the specific treatments he received.

\section{CASE PRESENTATION}

We report a 43-year-old man who presented to his general practitioner (GP) after 12 hours of fevers, rigors, severe abdominal cramps, nausea, vomiting and diarrhoea. His main complaint was intense epigastric pain radiating through to his back. The GP noted he was centrally cyanosed, tachypnoeic, febrile $\left(39.5^{\circ} \mathrm{C}\right)$ and intermittently drowsy, so urgent transfer to hospital by ambulance was arranged. He was promptly attended in the emergency department, where worsening tachypnoea, abdominal pain, and profound central and peripheral cyanosis were noted. His skin was generally mottled and dusky, and there was evolving purple discolouration of his fingers, toes, nose, ears and lips. His extremities were cold to touch. He was distressed and mildly confused. Focused neurological, respiratory and abdominal examinations were otherwise unremarkable. Face mask oxygen was administered, intravenous access was secured, and $3000 \mathrm{~mL}$ intravenous crystalloid was given within the first 2 hours. Blood cultures were taken by separate venipuncture, but only after he had received his first dose of intravenous antibiotics. Parenteral opioid analgesia was titrated to relieve pain and distress.

Significant medical history included hereditary spherocytosis with splenectomy in childhood. $\mathrm{He}$ had maintained prophylactic immunisation but did not take regular antibiotics. He suffered a rightsided precentral gyrus infarct (stroke) in early adulthood, after which an incidental patent foramen ovale was detected. Rehabilitation was complete, with no residual neurological deficits.

Initial blood results demonstrated marked neutrophilia with bands, acute kidney injury and DIC. Liver function tests were mildly elevated, and serum lipase was normal (table 1). Chest X-ray and 12-lead ECG were both unremarkable. CT of his abdomen was reported as showing bilateral perinephric stranding and pancreatic inflammation. Microbiology samples of blood and urine were sent. Pneumococcal DNA was detected in blood via PCR, and antigen for S. pneumoniae was detected in urine.

Following the first $1000 \mathrm{~mL}$ intravenous crystalloid bolus, the patient's blood pressure incremented slightly and his mental state improved. However, the prolonged central capillary refill time, mottled skin, and deep cyanosis of his ears, nose, lips, hands and feet visibly worsened, despite further volume resuscitation. A radial arterial line was inserted for haemodynamic monitoring and blood gas analysis, 
Findings that shed new light on the possible pathogenesis of a disease or an adverse effect

\begin{tabular}{|c|c|c|c|c|c|}
\hline \multicolumn{2}{|l|}{ Vitals (ED) } & \multicolumn{2}{|l|}{ Blood (0-8 hours) } & \multicolumn{2}{|c|}{ Blood gas analysis (ICU) } \\
\hline BP & $103 / 55 \mathrm{~mm} \mathrm{Hg}$ & Haemoglobin & $135 \mathrm{~g} / \mathrm{L}$ & $\mathrm{pH}$ & 7.32 \\
\hline Heart rate & 105 beats/min & White cell count & $18.9 \times 10^{9} / \mathrm{L}$ & $\mathrm{PaO}_{2}\left(\mathrm{FiO}_{2} 0.5\right)$ & $127 \mathrm{~mm} \mathrm{Hg}$ \\
\hline Respiratory rate & 30 breaths $/ \mathrm{min}$ & Bands & $8.3 \times 10^{9} / \mathrm{L}$ & $\mathrm{PaCO}_{2}$ & $22 \mathrm{~mm} \mathrm{Hg}$ \\
\hline Saturation & $95 \%\left(15 \mathrm{~L} \mathrm{O}_{2}\right)$ & Platelet count & $98 \times 10^{9} / \mathrm{L}$ & $\mathrm{HCO}_{3}^{-}$ & $12.1 \mathrm{mmol} / \mathrm{L}$ \\
\hline GCS & 15 (drowsy) & Urea & $17.2 \mathrm{mmol} / \mathrm{L}$ & Base excess & $-11.5 \mathrm{mmol} / \mathrm{L}$ \\
\hline \multirow[t]{2}{*}{ LFTs (peak: hours postadmission) } & & Creatinine & $286 \mu \mathrm{mol} / \mathrm{L}$ & Lactate & $6.6 \mathrm{mmol} / \mathrm{L}$ \\
\hline & & INR & 3.4 & Glucose & $4.6 \mathrm{mmol} / \mathrm{L}$ \\
\hline Albumin (8hours) (trough) & $26 \mathrm{~g} / \mathrm{L}$ & aPTT & $103 \mathrm{~s}$ & Sodium & $134 \mathrm{mmol} / \mathrm{L}$ \\
\hline ALP (11 hours) & 104 units/L & Fibrinogen & $1.8 \mathrm{~g} / \mathrm{L}$ & Potassium & $3.7 \mathrm{mmol} / \mathrm{L}$ \\
\hline GGT (0 hour) & 39 units/L & Lipase & 147 units/L & Chloride & $109 \mathrm{mmol} / \mathrm{L}$ \\
\hline ALT (11 hours) & 140 units/L & $\mathrm{C}$ reactive protein & $212 \mathrm{mg} / \mathrm{L}$ & Calcium (ionised) & $0.86 \mathrm{mmol} / \mathrm{L}$ \\
\hline AST (11 hours) & 266 units/L & Lactate dehydrogenase & 836 units/L & & \\
\hline Bilirubin (33 hours) & $101 \mu \mathrm{mol} / \mathrm{L}$ & Haptoglobin & $<0.3 \mathrm{~g} / \mathrm{L}$ & & \\
\hline
\end{tabular}

ALP, alkaline phosphatase; ALT, alanine aminotransferase; aPTT, activated partial thromboplastin time; AST, aspartate aminotransferase; BP, blood pressure; ED, emergency department; GGT, gamma-glutamyl transferase; ICU, intensive care unit; INR, international normalised ratio; LFT, liver function tests.

revealing a high anion gap metabolic acidosis, elevated lactate and respiratory alkalosis, all typical of early sepsis (table 1).

Despite haemodynamic stability, ongoing clinical concern warranted admission to intensive care unit (ICU), where central venous access was inserted. A transthoracic echocardiogram revealed a well-filled heart with a normal systolic ejection fraction and no valvular lesions. 'Normal' function, however, was considered inadequate owing to the unimproved peripheral circulatory signs, persistent lactic acidosis and now established anuria, despite adequate blood pressure. Milrinone was commenced at $0.25 \mu \mathrm{g} / \mathrm{kg} / \mathrm{min}$, without bolus, to improve peripheral perfusion and augment cardiac output. Over the next $20 \mathrm{~min}$, his ears, nose, lips and central capillary refill all visibly improved, and urine appeared. Despite easily palpable radial and dorsalis pedis pulses (also audible on Doppler ultrasound), both hands and feet remained cold and were now numb. His digits were symmetrically purple-black. Over the next few hours, this numbness was gradually replaced by pain and paraesthesiae, particularly in the fingers.

In the absence of active bleeding, the DIC was not treated with clotting factors or plasma products owing to concerns these could increase the risk of microvascular thrombi in his digits and potentially worsen the situation.

Early referrals were made to several specialty teams, including vascular surgeons, to consider the optimal management of the profound digital ischaemia. The treatments recommended, and those provided, are detailed in table 2.

The patient was competent to provide consent for his own care throughout his illness, although in hindsight he recognised his 'thoughts were clouded' in the first 24 hours of his admission. He was most concerned about any intervention that might increase his risk of another stroke.

Catheter-directed, intra-arterial thrombolysis was discussed and dismissed. There is no consensus on agent or dosage, and the risk of inadvertent systemic thrombolysis is unknown in the setting of concurrent administration into multiple vessels in the presence of DIC. He was willing to accept systemic anticoagulation with unfractionated heparin, as this is commonly used in ICUs and can be rapidly reversed with protamine. The theoretical therapeutic intent was thrombus prevention. This was started 16 hours after ICU admission, using a standard protocol.

The patient reported feeling an instant benefit with intravenous heparin. He said that his fingers felt warmer and started to regain feelings, although more painful ones. Objectively, there was little improvement. The visible zones of colour demarcation were not appreciably different, and the digits remained cold to touch. The infusion was continued and monitored by serial activated partial thromboplastin time (aPTT).

Glyceryl trinitrate (GTN) paste was applied to his hands but was soon removed because of severe headache, which then resolved. Subsequent systemic administration of intravenous GTN provided no obvious benefit, or side effects, but it was continued, nevertheless.

A right-sided axillary plexus block with lignocaine, epinephrine and clonidine provided temporary and welcome analgesia to the right hand. The block was technically successful in that the arm lost motor function and his wrist and forearm were appreciably warmer to touch, but there was no visible indication of circulatory improvement in the hand. It was thus not repeated on the left side. Additional concern over possible cumulative local anaesthetic toxicity was another factor in that decision. The motor block lasted over 8 hours.

Over the next 72 hours, there was a steady and marked improvement in both the appearance and function of all four limbs, more so in his hands than his feet. This seems to be the usual pattern reported in other cases. ${ }^{47}$ Milrinone was ceased after 24 hours, GTN was continued for 68 hours, and heparin was continued for 72 hours. Gabapentin and oxycodone made his pain bearable. At the time of ICU discharge, the patient's fingers were no longer purple, but they were still dusky and swollen (figure 1). Gangrenous demarcation was evident in both feet (figures 2 and 3 ).

Topical application of alcohol and betadine-soaked dressings began under the surgical team's direction after transfer to the ward. He was provided hand therapy by an allied health team and daily review by an acute pain service.

\section{DIFFERENTIAL DIAGNOSIS}

Purpura associated with clinical signs of shock is strongly suggestive of sepsis, but can also occur in conditions causing acute haemolysis such as haemolytic uraemic syndrome or thrombotic thrombocytopaenic purpura. Our patient had an elevated lactate dehydrogenase (LDH) with a borderline low haptoglobin (table 1), but other markers of haemolysis, including blood film examination and reticulocyte count, were not impressive, and thrombocytopaenia was only mild. Toxic neutrophilia with marked left shift was the predominant finding, consistent with bacterial infection. 


\section{Findings that shed new light on the possible pathogenesis of a disease or an adverse effect}

Table 2 Treatment options considered

\begin{tabular}{|c|c|c|}
\hline Treatment & Theoretical benefits & Perceived effects \\
\hline $\begin{array}{l}\text { Intravenous milrinone } \\
\text { infusion }\end{array}$ & $\begin{array}{l}\text { Inodilatory effects in the context of good cardiac function to improve peripheral } \\
\text { perfusion. }\end{array}$ & $\begin{array}{l}\text { Improvement in perfusion to ears, nose and lips, central capillary } \\
\text { refill time, and urine output. Hands and feet remained cool and } \\
\text { cyanosed. }\end{array}$ \\
\hline Glyceryl trinitrate (GTN) & $\begin{array}{l}\text { Vasodilation to improve perfusion. Intravenous infusion titrated to headache and } \\
\text { blood pressure. Topical GTN paste trialled prior to infusion, however ceased due } \\
\text { to headache. }\end{array}$ & $\begin{array}{l}\text { Steady-state rate } 50 \mu \mathrm{g} / \mathrm{min} \text { and } 68 \text { hours' duration. Nil } \\
\text { immediate improvement evident. }\end{array}$ \\
\hline Intra-arterial lignocaine & $\begin{array}{l}5 \mathrm{~mL} \text { of } 2 \% \text { lignocaine neat, opportunistically injected via the right radial arterial } \\
\text { line, for possible vasodilation. }\end{array}$ & $\begin{array}{l}\text { Nil immediate improvement evident, and arterial line } \\
\text { subsequently relocated to right dorsalis pedis for preferential } \\
\text { preservation of digital function. }\end{array}$ \\
\hline Axillary nerve block & $\begin{array}{l}\text { Performed on dominant right arm with } 30 \mathrm{~mL} \text { of } 1.5 \% \text { lignocaine/1:400 } 000 \\
\text { epinephrine and } 50 \mu \mathrm{g} \text { of clonidine, under ultrasound guidance. Rationale of } \\
\text { vasodilation secondary to reduced sympathetic tone and improved perfusion. } \\
\text { Lower risk than stellate ganglion blockade. }\end{array}$ & $\begin{array}{l}\text { Excellent motor and sensory block lasting several hours was } \\
\text { achieved, with notable increase in temperature of the forearm } \\
\text { and wrist, but no change in the temperature or colour of digits. } \\
\text { Not repeated on other side based on risk to benefit judgement. } \\
\text { Subjectively from the patient, this was the second most helpful } \\
\text { intervention; however, there was no eventual difference in } \\
\text { outcome between arms. }\end{array}$ \\
\hline Stellate ganglion block & $\begin{array}{l}\text { Rationale of vasodilation secondary to reduced sympathetic tone and improved } \\
\text { perfusion. Refused by the patient on the basis of bleeding risk. }\end{array}$ & - \\
\hline Epidural catheter & $\begin{array}{l}\text { Rationale of vasodilation secondary to reduced sympathetic tone and improved } \\
\text { perfusion. Priority given to maintenance of anticoagulant therapy, thus } \\
\text { contraindicated. }\end{array}$ & - \\
\hline Systemic anticoagulation & $\begin{array}{l}\text { Systemic unfractionated heparin infusion to maintain aPTT of } 60-90 \text { s. Started } \\
16 \text { hours post-ICU admission. Prevention of microthrombi in the setting of DIC. }\end{array}$ & $\begin{array}{l}\text { Greatest subjective improvement as noted by the patient. } \\
\text { Objectively, no immediate improvement evident. }\end{array}$ \\
\hline Thrombolysis & $\begin{array}{l}\text { Thrombolysis in the setting of microthrombi subsequent to sepsis-induced DIC. } \\
\text { Systemic thrombolysis declined by the patient, as he was not willing to accept any } \\
\text { risk of intracerebral bleed. Regional (catheter-directed) technique not pursued due } \\
\text { to limited evidence of benefit, scant descriptions of appropriate technique and } \\
\text { potential of harm to vital arteries from instrumentation. }\end{array}$ & - \\
\hline Intra-arterial prostacyclin & Not pursued due to similar limitations as with regional thrombolysis. & - \\
\hline Hyperbaric oxygen & Not available at our institution, and not clearly indicated in this setting. & - \\
\hline
\end{tabular}

DIC, disseminated intravascular coagulopathy; ICU, intensive care unit.

Other conditions that may be responsible for purpura fulminans and symmetrical peripheral gangrene (SPG) include myeloproliferative disorders, lymphoproliferative disorders, vasculitides, uncontrolled proinflammatory disorders and antiphospholipid syndrome. ${ }^{4}$ These were all screened for in a barrage of initial tests.

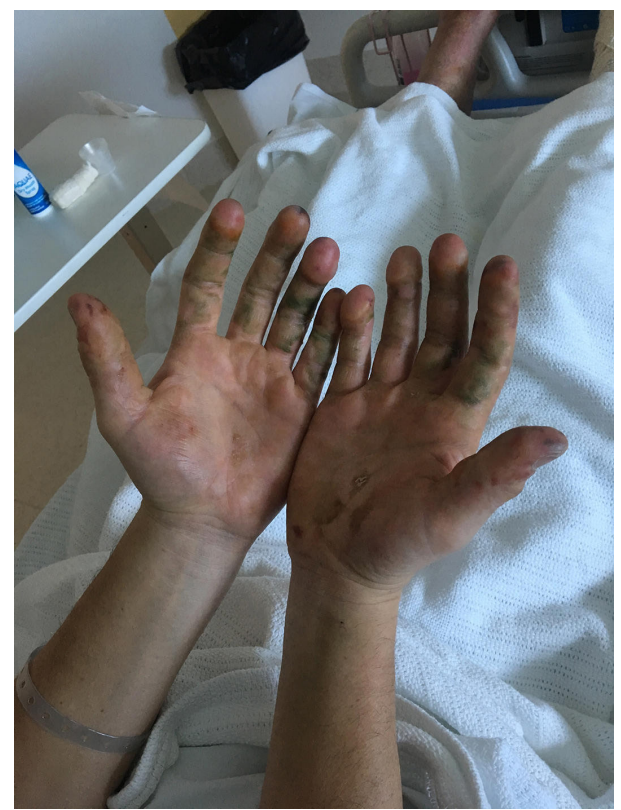

Figure 1 Digital ischaemia of the hands following discharge from the intensive care unit.
An isolated monoclonal IgG kappa immunoglobulin was detected by serum electrophoresis and was followed up after ICU discharge. Bone marrow trephine and extended light chain analysis confirmed previously undiagnosed multiple myeloma. Given that the SPG had

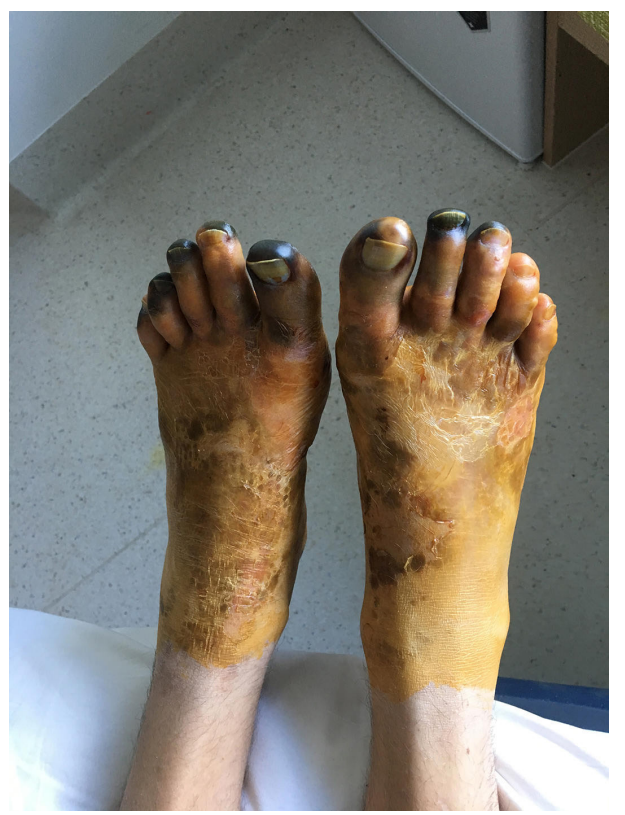

Figure 2 Purpura fulminans demonstrated on the dorsal aspect of the feet stained with iodine, following discharge from the intensive care unit. 


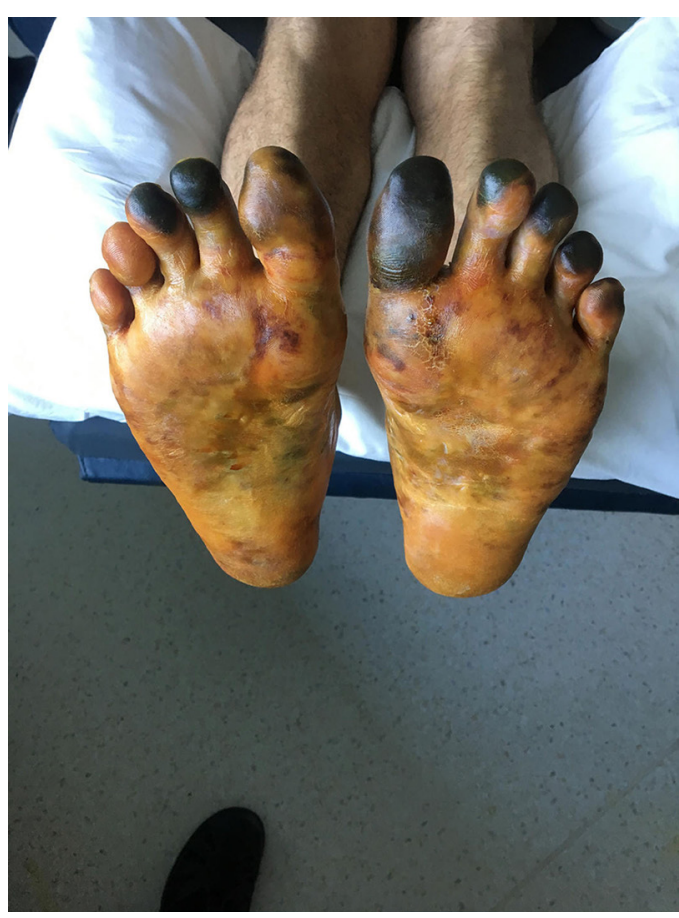

Figure 3 Purpura fulminans demonstrated on the plantar aspect of the feet stained with iodine, following discharge from the intensive care unit.

dissipated by this time, we do not believe it was the fundamental cause of the presentation, although we acknowledge it could have been a contributing factor. He has subsequently undergone chemotherapy and stem cell transplantation with an encouraging response.

Whether his hereditary spherocytosis also contributed to the syndrome, or not, is unclear. The condition is known to affect the transit of red cells through the microcirculation. Splenectomy increases susceptibility to encapsulated bacteria, such as pneumococcus, and it may also have preserved his platelet levels and masked the severity of his DIC.

\section{OUTCOME AND FOLLOW-UP}

This patient's hands ultimately made a full recovery, intact. His feet were less fortunate, with seven toes eventually amputated. As part of his rehabilitation, this man resumed playing the piano. He described it like playing on keys made of broken glass at first, and his playing endurance was limited by pain and fatigue. Many months later he had improved to the point of resuming public performances. He has gladly given his consent to publish this information for the benefit of others.

\section{DISCUSSION}

'Purpura fulminans' is a spectrum of clinical presentations that range from florid, widespread purpura in a general distribution over the entire body, to relatively isolated but symmetrical purpura and ischaemia of the acral extremities (ie, hands, feet, ears, nose, penis and lips). The latter aspect is always present, and when generalised purpura is absent it is classically called SPG. ${ }^{4}$ Our patient falls into this latter category. In all forms there is tissue necrosis in the absence of large artery occlusion. ${ }^{4689}$

Although this case meets the definitions of overwhelming postsplenectomy sepsis, the focus of our discussion centres on the digital ischaemic complication, which is a recognised complication of any form of sepsis. It is, however, most commonly associated with Neisseria meningitidis and S. pneumoniae. ${ }^{8} 1011$ Pneumococcus was detected in our patient by serum PCR and urinary antigen. Blood cultures were negative but were taken after antibiotic administration. In sepsis with evolving purpura, it is common practice to prioritise the timely administration of antibiotics, given the known high mortality, and the sensitivity of the likely organisms. Piperacillin/tazobactam and vancomycin were chosen for broad empirical cover, which were rationalised to benzylpenicillin after 48 hours, in the absence of other positive cultures.

There is limited understanding of the underlying pathophysiology, and we hesitate to oversimplify what is undoubtedly a complex process. Proposed mechanisms include an acute imbalance in prothrombotic and anticoagulant factors leading to microcirculatory occlusion; intense vasoconstriction secondary to natural physiological responses to shock and high-dose vasopressor administration; and endothelial damage from immune complexes. ${ }^{3-691012-15}$ It may be that all of these occur concurrently. We are inclined to pursue the first hypothesis as being the richest area for potential therapeutic interventions.

Our patient had biochemical signs of mild hepatic and renal injuries that are common in sepsis, although these did not progress to overt organ failure. His liver function tests (LFT) derangements (table 1) resolved over the next few days. His high international normalised ratio (INR) was attributed to DIC, which corrected without intervention, and his blood glucose was always preserved. The serum albumin was mildly reduced, which may have reflected a transient reduction in synthetic hepatic function. Elevations in aspartate aminotransferase (AST), alanine aminotransferase (ALT) and LDH are not linear in their relation to the extent of underlying liver damage, ${ }^{16}$ so while these appear mild they could be consistent with 'shock liver'. This is thought to cause a decay in the natural anticoagulant effects of protein $\mathrm{C}$ and antithrombin, which occurs more rapidly than the decay in procoagulant factors, when hepatic synthetic function is seriously affected by sepsis and septic shock. ${ }^{6}{ }^{14}$ We did not specifically measure antithrombin, protein $\mathrm{C}$ or other factors as this is not routine in Australian ICU practice for acute sepsis or DIC management, and by the time this information had come to light our opportunity to do so in this patient had passed.

With respect to vasoconstriction, the majority of therapies recommended by our colleagues focused on relieving vasospasm, and a number of papers have suggested that vasopressors are responsible or strongly contributory to the syndrome. ${ }^{9} 12$ Early

Table 3 Case reports describing benefits of sympathetic blockade

\begin{tabular}{|c|c|}
\hline History of patient & Described effect of sympathetic blockade \\
\hline $\begin{array}{l}\text { A 71-year-old woman with Enterococcus faecalis sepsis received stellate ganglion } \\
\text { block. }\end{array}$ & $\begin{array}{l}\text { Complete resolution of digital ischaemia within an hour of stellate ganglion block, with } \\
\text { the effects lasting for } 2 \text { days. }{ }^{17}\end{array}$ \\
\hline $\begin{array}{l}\text { A 40-year-old woman with pneumococcal sepsis received stellate ganglion and } \\
\text { brachial plexus blocks. }\end{array}$ & Improved peripheral perfusion. ${ }^{35}$ \\
\hline $\begin{array}{l}\text { A } 16 \text {-month-old, asplenic child with sepsis, with a pre-existing traumatic brachial } \\
\text { plexus palsy. }\end{array}$ & $\begin{array}{l}\text { Sparing of purpura fulminans on the limb with palsy. Other protective mechanisms such as } \\
\text { decreased muscle use and oxygen consumption may have contributed. }{ }^{10}\end{array}$ \\
\hline
\end{tabular}


case reports, however, found that only 10\%-20\% of patients had a temporal relationship of the syndrome with vasopressor use. $^{3469}$ Given that SPG developed fully and rapidly in this patient without vasopressors ever being used, they cannot be incriminated. This does not refute that vasopressors can contribute to the syndrome, but we feel it turns the focus to other mechanisms. Administration of excessive intravenous fluid may further reduce depleted levels of natural anticoagulants protein $\mathrm{C}$ and antithrombin by haemodilution, and thus worsen the microcirculatory changes. ${ }^{6}$ Perhaps this occurred in our patient, as his SPG developed more rapidly than the majority of cases previously reviewed. ${ }^{469}$ It begs the question whether vasopressors may have been, ironically, a better option than volume loading.

The benefits of therapeutic vasodilation may also be questioned. Milrinone appeared to improve general skin perfusion and some of the extremity cyanosis, particularly in the nose, ears and lips. Perhaps it was reversing endogenously mediated selective vasoconstriction, or perhaps this just reflected an increase in cardiac output. GTN provided no additional benefit. Calcium channel blockers were contraindicated in the presence of shock with inotrope therapy. The refractory signs of marked ischaemia in all digits with persistently palpable peripheral pulses suggest to us that microcirculatory occlusion was the predominant feature in these unresponsive areas.

Vasodilation by local sympathetic blockade has also been strongly advocated, particularly through the use of stellate ganglion anaesthesia (table 3). ${ }^{3510} 17$ Therapeutic anticoagulation precluded this technique. Instead, an axillary brachial plexus block was successfully performed on the right arm. The result, however, was not convincing enough to persuade us to perform another block, or to block the left arm, and it is noteworthy that there was no difference in the long-term outcome between the treated and untreated sides.

Therapies of benefit as suggested by case reports are outlined in Box 1.

We must also acknowledge the potential confounding influences of hereditary spherocytosis, which prolongs the transcapillary transport of red blood cells. There is also the possibility his undiagnosed multiple myeloma may have contributed to the clinical picture. It is perhaps noteworthy that neither of these conditions were actively treated, acutely, yet his ischaemic changes steadily improved.

Box 1 Therapies to treat purpura fulminans described in the literature

Therapies to improve perfusion by regional or systemic vasodilation.

- Vasodilator infusion.

- Milrinone/dobutamine.

- Glyceryl trinitrate.

- Topical nitrates.

- Oral vasodilators, for example, calcium channel blockers.

- Sympathetic blockade with local anaesthetic administration to sympathetic ganglia or major nerve plexi.

Therapies to improve blood rheology and its passage through the microcirculation.

- Anticoagulant agents.

- Antiplatelet agents (prostacyclin).

- Thrombolytic agents.

- Hyperbaric oxygen.
Table 4 Level of evidence of available literature

\begin{tabular}{|c|c|c|}
\hline Paper & Level of evidence & $\begin{array}{l}\text { Grade of } \\
\text { recommendation }\end{array}$ \\
\hline $\begin{array}{l}\text { Symmetrical peripheral gangrene } \\
\text { (purpura fulminans) complicating } \\
\text { pneumococcal sepsis }\end{array}$ & $\begin{array}{l}4 \\
\text { Case series of } 10 \\
\text { patients }\end{array}$ & C \\
\hline $\begin{array}{l}\text { Symmetrical peripheral gangrene: } \\
\text { association with noradrenaline } \\
\text { administration }\end{array}$ & $\begin{array}{l}4 \\
\text { Case series of } 4 \\
\text { patients }\end{array}$ & C \\
\hline $\begin{array}{l}\text { Symmetrical peripheral gangrene } \\
\text { caused by septic shock }\end{array}$ & $\begin{array}{l}4 \\
\text { Case series of } 3 \\
\text { patients }\end{array}$ & C \\
\hline $\begin{array}{l}\text { Digital ischemia complicating } \\
\text { pneumococcal sepsis: reversal with } \\
\text { sympathetic blockade }\end{array}$ & $\begin{array}{l}4 \\
\text { Case report of a } \\
\text { single patient }\end{array}$ & C \\
\hline $\begin{array}{l}\text { Ultrasound-guided bilateral stellate } \\
\text { ganglion blockade to treat digital } \\
\text { ischemia in a patient with sepsis: a } \\
\text { case report }\end{array}$ & $\begin{array}{l}4 \\
\text { Case report of a } \\
\text { single patient }\end{array}$ & C \\
\hline $\begin{array}{l}\text { The protective effect of brachial plexus } \\
\text { palsy in purpura fulminans }\end{array}$ & $\begin{array}{l}4 \\
\text { Case report of a } \\
\text { single patient }\end{array}$ & C \\
\hline $\begin{array}{l}\text { Meningococcal sepsis and purpura } \\
\text { fulminans: the surgical perspective }\end{array}$ & $\begin{array}{l}4 \\
\text { Case report of a } \\
\text { single patient }\end{array}$ & C \\
\hline $\begin{array}{l}\text { The role of microvascular thrombosis } \\
\text { in sepsis }\end{array}$ & $\begin{array}{l}5 \\
\text { Based on physiology }\end{array}$ & D \\
\hline
\end{tabular}

C, case-control study or systematic review of these studies; D, case series.

As this patient's livelihood depended on his hands, we were compelled to actively review the evidence and to consult with our colleagues from other specialties for their opinions on the best treatment. Different medical or surgical specialist groups bring equal passion for, and confidence in, their preferred techniques, but with limited evidence to support their suggestions (table 4). A common feature of all of these recommendations is that they were translations of techniques used for other illnesses, such as Raynaud's or larger arterial thromboses, in the absence of sepsis. Our patient was an intelligent and motivated man who was able to articulate where his priorities lay. He decided he would rather lose his fingers than suffer another stroke, and this, thankfully, curbed enthusiasm for adventurous use of thrombolytic agents. We can never be sure that we made the right decisions together, but we are reasonably comfortable that our therapies align with emerging hypotheses about this condition. We are pleased that he retained his enjoyment in music and has the capacity to pursue his career. We believe that future research should focus on the microcirculation, and that until further evidence is available, if another patient presented with features of SPG or purpura

\section{Learning points}

- This case supports emerging hypotheses that imbalances of coagulation factors and natural anticoagulants lead to thrombosis in the microcirculation, causing symmetrical peripheral gangrene (SPG) and purpura fulminans in sepsis.

- Vasopressors were never administered and yet this patient's SPG developed rapidly and severely.

- Milrinone, a systemic vasodilator and inotrope, most convincingly reversed the visible signs in non-digital extremities, but not the fingers and toes.

- Systemic anticoagulation with heparin apparently provided the greatest benefit for this patient. 
fulminans, we would be comfortable to use systemic anticoagulation with heparin, unless contraindicated, and to ensure that the shock state is adequately reversed with inodilators, when possible. Avoidance of vasopressors is preferred, but we would be comfortable to use them, if required, to support the circulation. We will also measure protein $\mathrm{C}$, antithrombin and other clotting factors in the acute phase, and consider plasma replacement if volume is required. We hope this case report will assist other clinicians confronting this devastating condition.

Contributors VK: primary author, literature review, first draft, editing, formatting, patient liaison/consent. RSS: secondary author, literature review, editing, patient liaison.

Funding The authors have not declared a specific grant for this research from any funding agency in the public, commercial or not-for-profit sectors.

\section{Competing interests None declared.}

Patient consent for publication Obtained.

Provenance and peer review Not commissioned; externally peer reviewed.

Open access This is an open access article distributed in accordance with the Creative Commons Attribution Non Commercial (CC BY-NC 4.0) license, which permits others to distribute, remix, adapt, build upon this work non-commercially, and license their derivative works on different terms, provided the original work is properly cited and the use is non-commercial. See: http://creativecommons.org/ licenses/by-nc/4.0\%.

\section{REFERENCES}

1 Forrest J, McIntyre P, Burgess M, et al. Pneumococcal disease in Australia Health.gov. au, 2004. Available: http://health.gov.au/internet/main/publishing.nsf/content/cdapubs-cdi-2000-cdi2404-cdi2404a.htm
2 Toms C, de Kluyver R, Toms C, et al. Invasive pneumoccal disease in Australia 2011 and 2012 Health.gov.au, 2016. Available: http://www.health.gov.au/internet/main/ publishing.nsf/content/cda-cdi4002k.htm

3 Johansen K, Hansen ST. Symmetrical peripheral gangrene (purpura fulminans) complicating pneumococcal sepsis. Am J Surg 1993;165:642-5.

4 Warkentin TE. Ischemic limb gangrene with pulses. N Eng/ J Med 2015;373:642-55.

5 Johansen K, Murphy T, Pavlin E, et al. Digital ischemia complicating pneumococcal sepsis: reversal with sympathetic blockade. Crit Care Med 1991;19:114-6.

6 Warkentin T. Microvascular thrombosis and ischaemic limb losses in critically ill patients. Hamostaseologie 2019;39:006-19.

7 Warner PM, Kagan RJ, Yakuboff KP, et al. Current management of purpura fulminans: a multicenter study. J Burn Care Rehabil 2003;24:119-26.

8 Shimbo K, Yokota K, Miyamoto J, et al. Symmetrical peripheral gangrene caused by septic shock. Case Reports Plast Surg Hand Surg 2015;2:53-6.

9 Warkentin TE. Symmetrical peripheral gangrene: mechanisms for limb loss in the ICU in patients with retained pulses. Clinical Pulmonary Medicine 2018;25:61-6.

10 Schade Willis TM, Hopp RJ, Romero JR, et al. The protective effect of brachial plexus palsy in purpura fulminans. Pediatr Neurol 2001;24:379-81.

11 Morris ME, Maijub JG, Walker SK, et al. Meningococcal sepsis and purpura fulminans: the surgical perspective. Postgrad Med J 2013;89:340-5.

12 Hayes MA, Yau EHS, Hinds CJ, et al. Symmetrical peripheral gangrene: association with noradrenaline administration. Intensive Care Med 1992;18:433-6.

13 Dixon B. The role of microvascular thrombosis in sepsis. Anaesth Intensive Care 2004;32:619-29.

14 Siegal DM, Cook RJ, Warkentin TE. Acute hepatic necrosis and ischemic limb necrosis. N Engl J Med 2012;367:879-81.

15 Gotts JE, Matthay MA. Sepsis: pathophysiology and clinical management. BMJ 2016;353.

16 Worthley LIG. Handbook of emergency laboratory tests. New York: Churchill Livingstone, 1996.

17 Bataille B, Nucci B, Mora M, et al. Ultrasound-Guided bilateral stellate ganglion blockade to treat digital ischemia in a patient with sepsis: a case report. Can J Anesth/J Can Anesth 2016;63:56-60.

Copyright 2019 BMJ Publishing Group. All rights reserved. For permission to reuse any of this content visit https://www.bmj.com/company/products-services/rights-and-licensing/permissions/

BMJ Case Report Fellows may re-use this article for personal use and teaching without any further permission.

Become a Fellow of BMJ Case Reports today and you can:

- Submit as many cases as you like

- Enjoy fast sympathetic peer review and rapid publication of accepted articles

- Access all the published articles

Re-use any of the published material for personal use and teaching without further permission

\section{Customer Service}

If you have any further queries about your subscription, please contact our customer services team on +44 (0) 2071111105 or via email at support@bmj.com.

Visit casereports.bmj.com for more articles like this and to become a Fellow 